\title{
Correlation among aortic stiffness, LV scar volume and diastolic dysfunction in hypertrophic cardiomyopathy: a cardiac MRI study Prabhakar Rajiah*, Randolph Setser and Scott D Flamm
}

\author{
Address: Cleveland Clinic Foundation, Cleveland, OH, USA \\ * Corresponding author
}

from 13th Annual SCMR Scientific Sessions

Phoenix, AZ, USA. 2I-24 January 2010

Published: 21 January 2010

Journal of Cardiovascular Magnetic Resonance 20 I0, I2(Suppl I):M4 doi:I0.I I86/I532-429X-I2-SI-M4

This abstract is available from: http://jcmr-online.com/content/I2/SI/M4

(C) 2010 Rajiah et al; licensee BioMed Central Ltd.

\section{Introduction}

We recently demonstrated that increased aortic stiffness as indicated by increased PWV is evident in patients with Hypertrophic cardiomyopathy (HCM), and is more pronounced in those with myocardial fibrosis. In parallel, left ventricular performance may be affected, and potentially represent an additional important factor in risk stratification.

\section{Purpose}

The purpose of this study was to determine the relationship among aortic stiffness as measured by PWV in MRI, LV scar volume, LV mass, diastolic function and LVOT gradients in patients with HCM.

\section{Methods}

Velocity encoded MRI was performed in 80 HCM and 35 normal control subjects. PWV was determined between the mid ascending and descending thoracic aorta. Delayed enhancement MRI was acquired for identification of myocardial fibrosis. Quantitative analysis of the scar was performed using advanced software package (Philips, The Netherlands). LV mass was evaluated by drawing endocardial and epicardial contours in cine-SSFP images. Diastolic function and LVOT gradients were evaluated by echocardiography. Diastolic function was graded from 03 and LVOT gradient was significant if $>30 \mathrm{~mm} \mathrm{Hg}$.

\section{Results}

Mean age was 55.4 years in HCM, and 45.3 years in controls. The prevalence of myocardial fibrosis in HCM was 53\%. PWV was significantly higher in HCM patients com- pared with controls $(8.51 \pm 3.9 \mathrm{~m} / \mathrm{s}$ vs $3.74 \pm 0.86 \mathrm{~m} / \mathrm{s}, \mathrm{p}$ $<0.0001)$. PWV was higher in HCM patients with fibrosis than those without $(9.8 \pm 4.4 \mathrm{~m} / \mathrm{s}$ vs $7.0 \pm 2.5 \mathrm{~m} / \mathrm{s}, \mathrm{p}<$ $0.0001)$, and higher in patients with severe fibrosis $(>10 \%$ of myocardial mass) than those with mild fibrosis $(11.1 \pm$ $6.3 \mathrm{~m} / \mathrm{s}$ vs $9.3 \pm 3.5 \mathrm{~m} / \mathrm{s}, \mathrm{p}<0.0001)$. However, there was no direct correlation between scar volume and aortic stiffness $\left(R^{2}=0.003\right.$, Fig 1$)$. There was also no direct correlation between LV mass and PWV $\left(\mathrm{R}^{2}=0.002\right)$. Diastolic dysfunction was seen in $73 \%$ of patients. PWV was significantly higher in HCM patients with diastolic dysfunction than those without $(9.1 \pm 4.3 \mathrm{~m} / \mathrm{s}$ vs $6.9 \pm 1.9 \mathrm{~m} / \mathrm{s}, \mathrm{p}<$ 0.0001 . Significant LVOT gradients at rest and provocation were seen in $51 \%$ and $84 \%$ of patients respectively, but there was no statistically significant difference of PWV in those with and without significant gradients.

\section{Conclusion}

Increased aortic stiffness, as indicated by increased PWV is evident in HCM patients, and is more pronounced in those with severe fibrosis than those with mild or no fibrosis, and in patients with diastolic dysfunction compared to those absent diastolic dysfunction. However, there is no direct correlation between abnormal PWV and scar volume, LV mass or LVOT gradient. 